\title{
One improved burial history recovery method and computer model establishment
}

\author{
Yangpeng $\mathrm{Zhu}^{1} \cdot$ Peng $\mathrm{Li}^{1}$ (D)
}

Received: 19 July 2017 / Accepted: 4 June 2018 / Published online: 21 June 2018

(c) The Author(s) 2018

\begin{abstract}
This paper which depended on the foundation of back strip method has established mathematic model to simulate stratum burial history, which considered the computation of stratum skeleton depth based on max depth and the equation-depth point on the procedure to recover stratum by stripping each layer, and put forward the enhanced restoration method taking layers group as studying object. Finally, the method has been applied to build the computer model and program automatic back strip algorithm successfully. Experiments have proved that the method is accurate, applicable, and extensible under the conditions of various complex strata.
\end{abstract}

Keywords Burial history restoration $\cdot$ Back-stripping technique $\cdot$ Stratum group restoration $\cdot$ Computer model establishment . Object oriented

\section{Introduction}

The burial history is the time and spatial sequence structure formed by a series of geological evolution, such as deposition, compaction, and denudation of strata in the time dimension. It describes a sedimentary and subsidence process of a basin since a sedimentary unit began to subsidence, which is a geodynamical evolutionary course through accumulation, compaction, uplift, and denudation (Liu and Chang 2003). Burial history modeling analyses the cumulative subsidence of selected chronostratigraphic horizons encountered in a well (Kamali and Rezaee 2003). The use of computer modeling software overcomes the disadvantages of the classical methods and enables the analysis of the burial history of sedimentary layers (Minkyu and Daekyo 2016). It brings more convenience greatly and enhanced efficiency greatly.

This paper established the mathematical model of burial history restoration based on the back-stripping method

If readers and relative researchers are interesting in this method and want to get source program, the email is ready, which is mzlp xa@126.com. Look forward to communicate with each other and make progress together.

Peng Li

mzlp_xa@126.com

1 Xian Shiyou University, Xi' an 710065, Shaanxi, China and considered the computation of stratum skeleton depth based on max depth of stratum and the equation-depth point accompanying with stripping each overlying strata, put forward the enhanced method taking the stratigraphic column as study object, which had been proved by experiment that it has higher theoretical and practical value for computer simulation of buried history.

\section{Correlational researcher}

So far, the back-stripping technique has highest accuracy and most application widely in the field of burial history restoration. So it has got more attention paid by researchers. Back-stripping technique built on the deposition and compaction theory is to strip top strata layer by layer from current stratigraphic column and make underlayers up to surface until all strata have been striped. The back-stripping procedure incorporated isostatic correction (Poprawa et al. 2010). On this process, it needs to take them into consideration that deposition sedimentary compaction, single-layer denudation, continuous multilayer erosion, and other geological events. Finally, the results expected are one serial stratigraphic column mapping to their geological ages. Because of the important role of back-stripping technique in the field of burial history restoration, many researchers at home and abroad have made study toward this technique. 
Gongxiang (1996) had studied the stratum compaction, then illustrated the method to use curves of normal compaction and under compaction and to restore quantificational original stratum thickness, and discussed detailedly the various questions in the process. At the same time, he had presented one method to enhance computation accuracy which reduced back-stripping computation interval. This has great practical value.

Xiaoping et al. (1998) had described the back-stripping methods meticulously, then came up with maximum depth method in order to implement computer automatic backstripping algorithm which insisted on restoring max-depth stratigraphic column. The computation steps of this new method had been introduced with clear thoughts and strong logicality by the authors. Experiments based on reality material showed that this method is right and accord with reality geological significance.

Xiangdong et al. (2010) had made new defines on backstripping method. They thought back-stripping method as one research thought which strip out one certain factor's application effect among the resulting of comprehensive function of multiple factors, and advocated the usage of standard back-stripping concept. The authors compared with various recovering methods of subsidence history and thought back-stripping method as penetration point to increase analyze precision of subsidence history.

Baozhen (2006) had used object-oriented design method to build computer model, adjusted burial history computation sequence, and unintegrated processing patterns and thought out one computation pattern combining forward model and inversion model, which had high application value.

Xiaorong (2004) had utilized the numerical basin model based on the finite-element method to simulate the pressuring effect of tectonic stress in sedimentary formations, which had took some factors on one-dimensional strip surface into consideration such as the strength of tectonic stress, the duration, and pattern of tectonic action, the physical diagenesis characteristics of formations. Some new understandings are proposed.

Some geological software had been applied to simulate burial history from oldest event to the most recent one, which can greatly represent the evolution of burial history. Papers (Paweł and Magdalena 2012; Van Keer et al. 1997; Senglaub et al. 2006; Narkiewicz et al. 2010) adopted the burial history results simulated by PetroMod software, designed in Germany, as the foundation of further researches. The SIGMA-2D basin modeling system (version 6) of the Japanese Oil, Gas and Metals National Corporation (JOGMEC), which described in detail by paper (Okui 1998), was used in paper (Premarathne et al. 2016), to simulate a basin's burial and thermal history along a 2D cross-section. In addition, in paper (Galushkin et al. 2014), The GALO computer program was used to model the thermal and burial histories of the Murzuq and Ghadames Basin, Libya. The GALO system uses a so-called "flat basin approach", which has more advantages compared to other basin modeling systems.

All the above papers have adopted the invariant principle of the thickness of the skeleton in the process of stripping to restore burial history. But computation to skeleton thickness is based on top depth and bottom depth of today's moment, this paper has thought that the top and bottom boundary should consider the max depth on the processing of sedimentary compaction; In addition, they regard single layer as study object and have not studied deeply the special geological event such as strata uplift and erosion. Even though Xiaoping et al. (1998) make explanation particularly, actually it is one way to combine forwarding model and inversion model.

Furthermore, Xiaoping et al. (1998) and Baozhen (2006) have declared the computer automatic back-stripping method which has great application value, but the computer model is not reasonable enough and not easy to adjust and extend function. Similarly, Baozhen (2006) has utilized more advanced finite-element methods to make numerical simulation; nonetheless, this method is too complex and lack of convenience. Minkyu and Daekyo (2016), Poprawa et al. (2010), Gongxiang (1996), Xiaoping et al. (1998), Xiaorong (2004), Paweł and Magdalena (2012), Premarathne et al. (2016), Senglaub et al. (2006), Galushkin et al. (2014), Narkiewicz et al. (2010), and Handhal et al. (2014) have not considered the processing of equation-depth point, and the burial history curve charts simulated by computer software, such as PetroMod, SIGMA-2D, and GALO, have not showed the equation-depth point as well, which should be the important geological marks and not neglected.

On the basis of above authors, this paper has been added the discuss of skeleton thickness computation of max depth and equation-depth point and put forward the restoration model of stratigraphic column which is able to process complex geological events including stratigraphic erosion and uplift. In the end, the restoration algorithm of stratigraphic column has been implemented with the concept of objectorient and been proved by experiment analyze that it is more reasonable and effective.

\section{Restoration model of burial history}

\section{Fundamental assumptions}

Among the researches on the technique of back-stripping method in the recovery of burial history, universally acknowledged assumptions is listed below (Xiaoping et al. 1998; Dengfeng et al. 2015): 
1. The total volume of the stratum is considered to be the sum of the volume of the skeleton and pore volume. On the process of formation compaction, skeleton volume has kept stability; change of pore volume causes the change of total volume. Variation of stratum volume has been reflected by thickness of stratum.

2. In the compaction process, the strata are not malleable horizontally, just are able to change vertically with the porosity change.

3. The stratum compaction is not invertible. Porosity of stratum is dominated by the max depth of compaction process. If the stratum experienced the moment of max depth and uplifted caused by erosion, the porosity have not change again.

In addition, to study conveniently, follow assumption has been proposed by this paper:

4. In the stratum compaction process, stratum thickness has become deeper and deeper with the skeleton thickness, which is linearly dependent on time.

\section{Math model}

1. The most main math model in the process of burial history restoration is compaction calibration model. The stacking and back-stripping methods (Liu and Chang 2003) in compaction model are used to reconstruct the burial history. With the thickness of stratum increasing, the compaction effect of the upper strata increases gradually, which causes stratum porosity minishing and then brings to thickness of stratum reducing. This pattern is expressed by the porosity-depth equation, which is proposed by Wei (1996), Anty (1930), and Hedberg (1936):

$\psi(z)=\varphi_{0} e^{-c z}$.

In this equation, $Z$ is the depth, $\psi(z)$ is the porosity of $Z$ depth, $\varphi_{0}$ is the porosity of ground surface, and $c$ is the compaction parameter. Porosity of ground surface and compaction parameter is all related with formation lithology.

In the compaction process, stratum skeleton thickness stays invariant and porosity reduces gradually. Then top depth of stratum is expressed by $Z_{\text {top }}$, and bottom depth is showed by $Z_{\text {base }}, Z_{\text {base }}>Z_{\text {top }} . H_{\text {porosity }}$ expresses thickness of porosity:

$H_{\text {porosity }}=\int_{Z_{\text {top }}}^{Z_{\text {base }}} \varphi_{0} e^{-c z} \mathrm{~d} z$

It is difficult to use computer to calculate integral. So this equation should be simplified:

$H_{\text {porosity }}=\frac{\varphi_{0}}{c}\left[e^{-c Z_{\text {top }}}-e^{-c Z_{\text {base }}}\right]$.
Stratum thickness of skeleton $H_{\text {skeleton }}$ can be expressed:

$H_{\text {skeleton }}=Z_{\text {base }}-Z_{\text {top }}-H_{\text {porosity }}$.

So, this equation is beneficial to design computer program.

2. In the compaction process, the condition caused by erosion has often existed, so the thickness of erosion should be considered on the process to restore stratum with erosion event. Concrete steps are that, in the moment of start of erosion event, total thickness of this stratum should add erosion thickness and cut the erosion thickness in the moment of end of erosion event. In the moment, between start moment and end moment, stratum porosity stays invariant. According to the assumption (4), rate of denudation is constant. The denudation layer thickness is not compacted upon the subsequent formation.

\section{Innovation point}

Calculate steps of back-stripping method have been illustrated in other papers (Okui 1998; Jiaren and Mingde 1995; Kaijun et al. 2005). This paper has made follow consideration based on former researchers.

$L(n)$ means one stratigraphic column $\left\{L_{1}, L_{2}, \ldots, L_{n}\right\}$, total layers are parameter $n, L_{i}$ represents stratum $i$. $L^{t}$ stands for the stratum status in the moment $t$. Every stratum has public properties, as shown in Table 1: $L_{i}$ [Name] means the name of stratum $L_{i}$ and so on. Lithological properties Lithology include three sub properties quoted by $L_{i}[$ Lithology] [name].

Table 1 Lithology properties table

\begin{tabular}{ll}
\hline Property name & Illustration \\
\hline Name & Name of stratum \\
Top & Top depth of stratum, unit: m \\
Base & Bottom depth of stratum, unit: $\mathrm{m}$ \\
Skeleton & Skeleton thickness of stratum, unit: $\mathrm{m}$ \\
PresentThickness & Thickness of stratum, unit: $\mathrm{m}$ \\
ErosionThickness & Erosion thickness of stratum, unit: $\mathrm{m}$ \\
DepositionAgeFrom & Start time of stratum deposition, unit: Ma \\
DepositionAgeTo & End time of stratum deposition, unit: Ma \\
ErosionAgeFrom & Start time of erosion, unit: Ma \\
ErosionAgeTo & End time of erosion, unit: Ma \\
Lithology & Lithology of stratum \\
Name & Name of lithology \\
InitPorosity & Initial porosity of lithology \\
CompactionFactor & Compaction parameter of lithology \\
\hline
\end{tabular}




\section{Skeleton thickness based on max depth}

In the process of restoration, the thickness of the skeleton remains the same before and after the compaction. It is the key of back-stripping algorithm. So the skeleton thickness of each stratum should be calculated out according to Formula (3) and Formula (4) before stratum recovering. During uplift, the compaction of the sediments is considered to be unchanged; that is, the compaction of a layer is equal to the compaction stage at the maximum burial depth. So, taking presence of erosion and uplift, sedimentary, and compaction into consideration, these formulas should be used to refer to the top and bottom boundary of the maximum depth of strata during the entire geologic period instead of the present status of stratum. The parameter $L_{i}[$ Skeleton] can be calculated according to follow chart in Fig. 1.

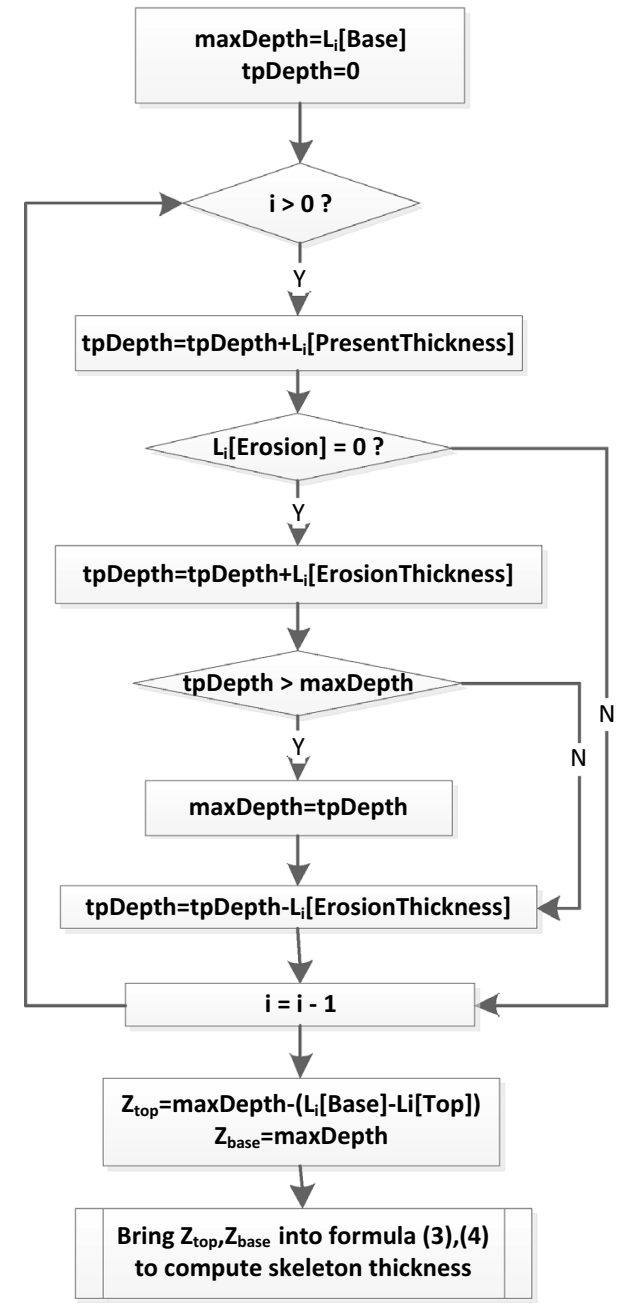

Fig. 1 Computation follow chart of skeleton thickness

\section{The processing of equivalent depth}

We use the scenario shown in Fig. 2 as example. In this figure, black broken line means depth curve of bottom boundary for certain stratum. During the process of stratum deposition, the upper layers gradually thickened and the strata were gradually compacted. Denudation started in the moment $t_{2}$ and ended in the moment $t_{1}$. During this period, stratum uplifted due to the development of denudation. Then strata were compacted until in the moment $t_{0}$, when stratum depth was deeper than in moment $t_{2}$. In the moment $t_{x}$, which was between $t_{1}$ and $t_{0}$, stratum depth should be the same as depth in moment $t_{2}$. So, the moment $t_{x}$ was named as the point of equivalent depth.

In the period $t_{2} \sim t_{x}$, the porosity of stratum was always consistent according assumption (3); in the period $t_{x} \sim t_{0}$, due to compaction, the porosity continues to minish. So stratum should be recovered in the moment $t_{x}$ regarded as key time point. Follow steps outlined below:

1. Computing equivalent rate of deposition $V_{\text {Deposion }}$

$V_{\text {Deposion }}=\frac{H_{\text {top }}}{\left(t_{1}-t_{0}\right)}$.

In this formula, $H_{\text {top }}$ stand for thickness needed to strip in the process of restoration from moment $t_{0}$ to moment $t_{1}$. Parameter $V_{\text {Deposion }}$ stands for the deposition rate of top stratum from moment $t_{1}$ to moment $t_{0}$.

2. Calculating the key time $t_{x}$ :

$t_{x}=\frac{\left(H_{\text {top }}-H_{\text {Erosion }}\right)}{V_{\text {Deposion }}}+t_{0}$.

In above formula, $H_{\text {top }}$ is the top boundary in moment $t_{0}$, and $H_{\text {Erosion }}$ is the erosion thickness of stratum.

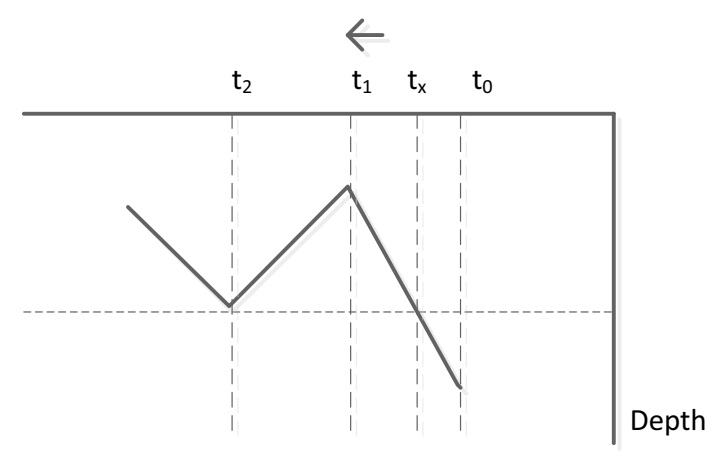

Fig. 2 Diagram of back stripping 


\section{Restoration model of stratigraphic column}

This paper has taken above math model and the condition of skeleton thickness based on max depth and the point of equivalent depth into consideration comprehensively to establish restoration model regarding stratigraphic column as study object. This model is able to get better restoration effect to the complex strata containing multiple layers denuded both completely and non-completely and continuous layers denuded. Finally, the key-value sets standing for (time, stratigraphic column) can be got, which is described by $L_{\text {result }}=\left\{\left(t_{1}, L^{t_{1}}\right),\left(t_{2}, L^{t_{2}}\right), \ldots,\left(t_{n}, L^{t_{n}}\right)\right\}$. This algorithm can be stated by follow chart in Fig. 3 .

\section{Experiment analysis}

To validate effect of this algorithm, this paper has made experiment using three groups stratum from Zhunger basin of china. The features of the three groups strata are listed as below:

1. Strata 1 are more common, which contains multiple erosion and whose max depth is in current time.

2. Strata 2 are made of some strata containing large thickness eroded, whose max depth is not in current time. Generally, these strata cover more geological condition which is more complex.

3. Strata 3 are the best complex. It includes continuous erosion, complete erosion and multiple erosion and other complicated geological conditions, which covers basically all geological conditions on the restoration process of burial history.

4. Basing on strata 3, the experiment has made on the condition that max depth is not considered in order to validate the influence of skeleton thickness based on max depth.

The parameters of the three strata are listed in Tables 2, 3 , and 4 .

Computer modeling of sedimentary processes was introduced to academia as a method of understanding of the processes of sediment transport, deposition, and erosion quantitatively (Minkyu and Daekyo 2016). Similarly, this paper used concept of object-orient built computer model shown in Appendix for above model and algorithm and program to implement these methods, depending on the platform of C\# computer language. Stratum information from Tables 2, 3, and 4 is inputted into programing in turn to attain the bottom depth of every stratum mapping to every key time, which are described in Figs. 4, 5, and 6. And in the three figures, top horizontal axis stands for time and vertical axis in right is depth; label 1-16 is the stratum $\mathrm{Q} \sim \mathrm{H}$ sequentially. Figure 7 is the result of strata 3 without considering skeleton thickness based on max depth. Comparing and analyzing these results, the two viewpoints can be got:

1. Observing the curves of stratum burial history, strata 1 had occurred four erosion geological events and dealt with four points of equivalent depth listed as 4.00, 93.35, 190.25, and 434.12; strata 2 had also experienced four erosion events and recognized and processed two points of equivalent depth; strata 3 had went through six erosion events and discovered five points of equivalent depth.

2. Comparing the curve chart of burial history for every stratum to original stratum data, the method putted forward by this paper can get better effect and distinguish for multiple erosions, sequential erosion, large erosion thickness, and others. And the result corresponds with actual geological condition better.

3. For confirming the rationality of the computation method for skeleton thickness based on max depth, experiments have been made to contrast the effect. The curve chart in Fig. 7 is the restoration result got by this paper's model without considering max depth. Comparing Figs. 6 and 7, the numerical value of top boundary in Fig. 7 is smaller than in Fig. 6. Referring to formula (3) and formula (4), when the max depth is larger than depth in current stratum status, compaction on stratum is greater and volume of porosity minishes better. Considering the assumption (3), so the volume of porosity for current strata should be the same as in the moment stratum got max depth and stratum thickness should be also consistent. Summarily, skeleton thickness based on max depth is rather larger than it with current depth of stratum. So that result of back-stripping is larger than applying current depth.

4. The result of experiment corresponds with mathematical logical reasoning. It is enough to certify the rationality to bring in max depth to compute skeleton depth.

To sum up, experimental results though the method of this paper accord with practice geological significance. It can demonstrate the evolution history more clearly. Meanwhile, it is also able to illustrate that the model and algorithm designed by this paper have more feasibility.

\section{Conclusion}

Based on previous researcher by other scholars and authors' further study for back-stripping method, this paper has bring in the following points referring to original math model:

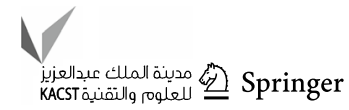




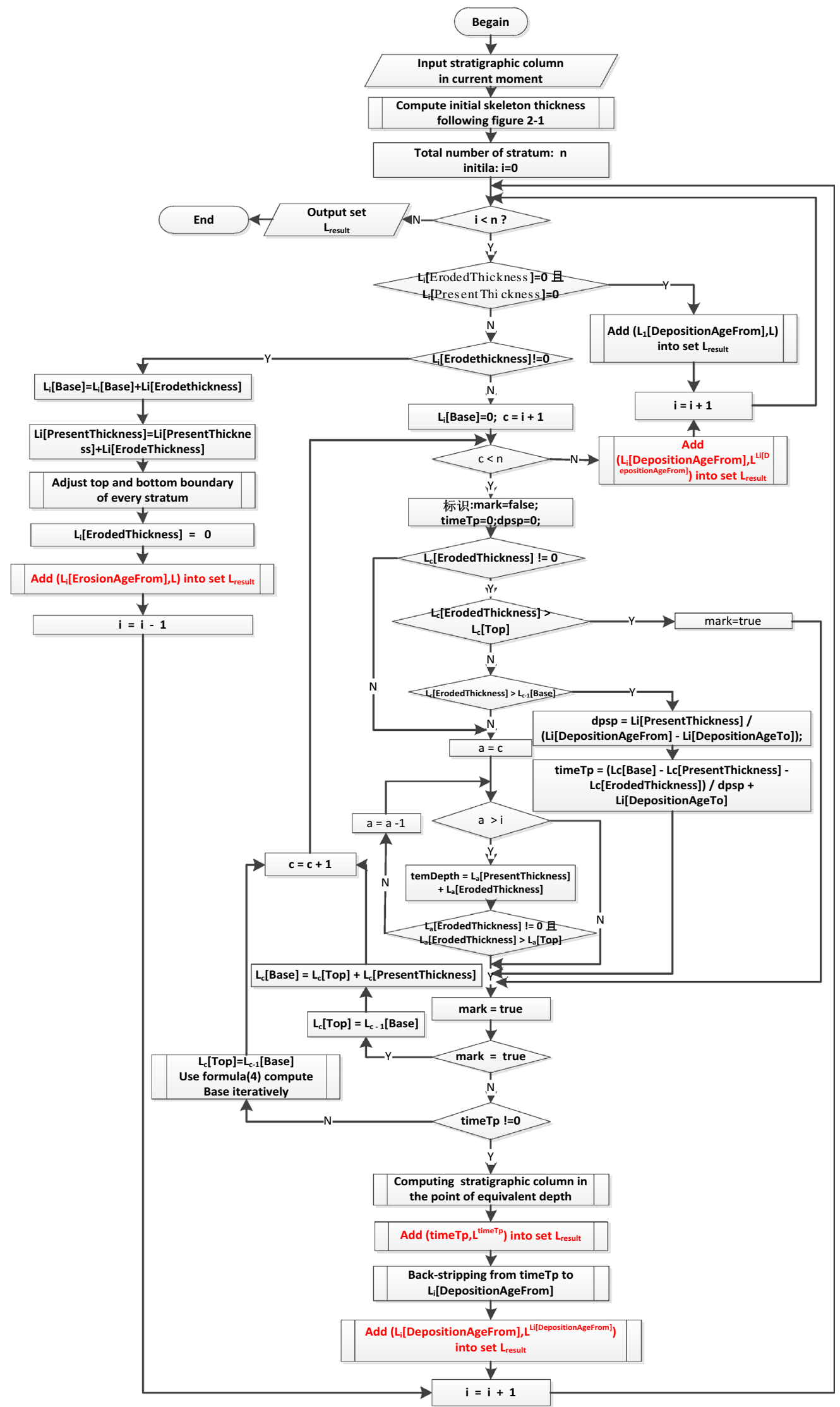

Fig. 3 Follow chart for recovering stratigraphic column 
Table 2 Strata 1

\begin{tabular}{|c|c|c|c|c|c|c|c|}
\hline \multirow[t]{2}{*}{ Stratum name } & \multirow[t]{2}{*}{ Thickness (m) } & \multirow[t]{2}{*}{$\begin{array}{l}\text { Erosion thick- } \\
\text { ness }(\mathrm{m})\end{array}$} & \multicolumn{2}{|c|}{$\begin{array}{l}\text { Deposition age } \\
\text { (Ma) }\end{array}$} & \multicolumn{2}{|c|}{$\begin{array}{l}\text { Erosion time } \\
\text { (Ma) }\end{array}$} & \multirow[t]{2}{*}{ Lithology } \\
\hline & & & From & To & From & To & \\
\hline Q & 500 & & 10 & 0 & & & Sandstone \\
\hline $\mathrm{N} 2$ & 0 & & 16 & 10 & & & Sandstone \\
\hline N1 & 0 & & 23 & 16 & & & Sandsilt \\
\hline $\mathrm{E}$ & 0 & & 56 & 23 & & & Shale \\
\hline K2 & 200 & 300 & 97 & 76 & 76 & 56 & Sandstone \\
\hline K1 & 800 & & 145 & 97 & & & Conglomerate \\
\hline $\mathrm{J} 3$ & 400 & 900 & 175 & 160 & 160 & 145 & Sandsilt \\
\hline $\mathrm{J} 1-2$ & 500 & & 208 & 175 & & & Shale \\
\hline $\mathrm{T}$ & 600 & & 354 & 208 & & & Sandsilt \\
\hline $\mathrm{P}$ & 300 & 1200 & 417 & 385 & 385 & 354 & Sandstone \\
\hline $\mathrm{C}$ & 800 & & 440 & 417 & & & Sandstone \\
\hline $\mathrm{D}$ & 200 & & 450 & 440 & & & Shale \\
\hline S & 400 & & 460 & 450 & & & Sandstone \\
\hline $\mathrm{O} 3$ & 600 & 1000 & 500 & 480 & 480 & 460 & Limestone \\
\hline O1-2 & 800 & & 520 & 500 & & & Limestone \\
\hline $\mathrm{H}$ & 600 & & 540 & 520 & & & Limestone \\
\hline
\end{tabular}

Table 3 Strata 2

\begin{tabular}{|c|c|c|c|c|c|c|c|}
\hline \multirow[t]{2}{*}{ Stratum name } & \multirow[t]{2}{*}{ Thickness (m) } & \multirow[t]{2}{*}{$\begin{array}{l}\text { Erosion thick- } \\
\text { ness }(\mathrm{m})\end{array}$} & \multicolumn{2}{|c|}{$\begin{array}{l}\text { Deposition age } \\
\text { (Ma) }\end{array}$} & \multicolumn{2}{|c|}{$\begin{array}{l}\text { Erosion time } \\
\text { (Ma) }\end{array}$} & \multirow[t]{2}{*}{ Lithology } \\
\hline & & & From & To & From & To & \\
\hline $\mathrm{Q}$ & 0 & & 10 & 0 & & & Sandstone \\
\hline $\mathrm{N} 2$ & 0 & & 16 & 10 & & & Sandstone \\
\hline N1 & 0 & & 23 & 16 & & & Sandsilt \\
\hline $\mathrm{E}$ & 0 & & 56 & 23 & & & Shale \\
\hline $\mathrm{K} 2$ & 200 & 300 & 97 & 76 & 76 & 56 & Sandstone \\
\hline $\mathrm{K} 1$ & 800 & & 145 & 97 & & & Conglomerate \\
\hline $\mathrm{J} 3$ & 400 & 900 & 175 & 160 & 160 & 145 & Sandsilt \\
\hline $\mathrm{J} 1-2$ & 500 & & 208 & 175 & & & Shale \\
\hline $\mathrm{T}$ & 600 & & 354 & 208 & & & Sandsilt \\
\hline $\mathrm{P}$ & 300 & 3000 & 417 & 385 & 385 & 354 & Sandstone \\
\hline $\mathrm{C}$ & 800 & & 440 & 417 & & & Sandstone \\
\hline $\mathrm{D}$ & 200 & & 450 & 440 & & & Shale \\
\hline S & 400 & & 460 & 450 & & & Sandstone \\
\hline $\mathrm{O} 3$ & 600 & 1000 & 500 & 480 & 480 & 460 & Limestone \\
\hline O1-2 & 800 & & 520 & 500 & & & Limestone \\
\hline $\mathrm{H}$ & 600 & & 540 & 520 & & & Limestone \\
\hline
\end{tabular}

1. Proposing the max depth as the top and bottom boundaries for computing skeleton thickness and describing the algorithm flow char, these make numeration of skeleton thickness more accurate.

2. Considering the point of equivalent depth in the process of restoration, it makes the whole restoration more reasonable.
3. Put forward that stratigraphic column should be as the object of study.

Finally, by algorithm implementation and experiment analysis, it has been demonstrated that the method is able to proceed with automatic back-stripping computation efficiently for continuous erosion, multiple erosion and other 
Table 4 Strata 3

\begin{tabular}{|c|c|c|c|c|c|c|c|}
\hline \multirow[t]{2}{*}{ Stratum name } & \multirow[t]{2}{*}{ Thickness (m) } & \multirow[t]{2}{*}{$\begin{array}{l}\text { Erosion thick- } \\
\text { ness }(\mathrm{m})\end{array}$} & \multicolumn{2}{|c|}{$\begin{array}{l}\text { Deposition age } \\
\text { (Ma) }\end{array}$} & \multicolumn{2}{|c|}{$\begin{array}{l}\text { Erosion time } \\
\text { (Ma) }\end{array}$} & \multirow[t]{2}{*}{ Lithology } \\
\hline & & & From & To & From & To & \\
\hline Q & 0 & & 10 & 0 & & & Sandstone \\
\hline $\mathrm{N} 2$ & 0 & & 16 & 10 & & & Sandstone \\
\hline N1 & 0 & & 23 & 16 & & & Sandsilt \\
\hline $\mathrm{E}$ & 0 & 400 & 56 & 45 & 45 & 23 & Shale \\
\hline $\mathrm{K} 2$ & 200 & 300 & 97 & 76 & 76 & 56 & Sandstone \\
\hline K1 & 800 & & 145 & 97 & & & Conglomerate \\
\hline $\mathrm{J} 3$ & 400 & 900 & 175 & 160 & 160 & 145 & Sandsilt \\
\hline $\mathrm{J} 1-2$ & 500 & & 208 & 175 & & & Shale \\
\hline $\mathrm{T}$ & 600 & & 354 & 208 & & & Sandsilt \\
\hline$P$ & 300 & 3000 & 417 & 385 & 385 & 354 & Sandstone \\
\hline $\mathrm{C}$ & 800 & 300 & 440 & 430 & 430 & 417 & Sandstone \\
\hline $\mathrm{D}$ & 200 & & 450 & 440 & & & Shale \\
\hline S & 400 & & 460 & 450 & & & Sandstone \\
\hline $\mathrm{O} 3$ & 600 & 1000 & 500 & 480 & 480 & 460 & Limestone \\
\hline O1-2 & 800 & 300 & 520 & 510 & 510 & 500 & Limestone \\
\hline $\mathrm{H}$ & 600 & & 540 & 520 & & & Limestone \\
\hline
\end{tabular}

Fig. 4 Curve chart of burial history for strata 1

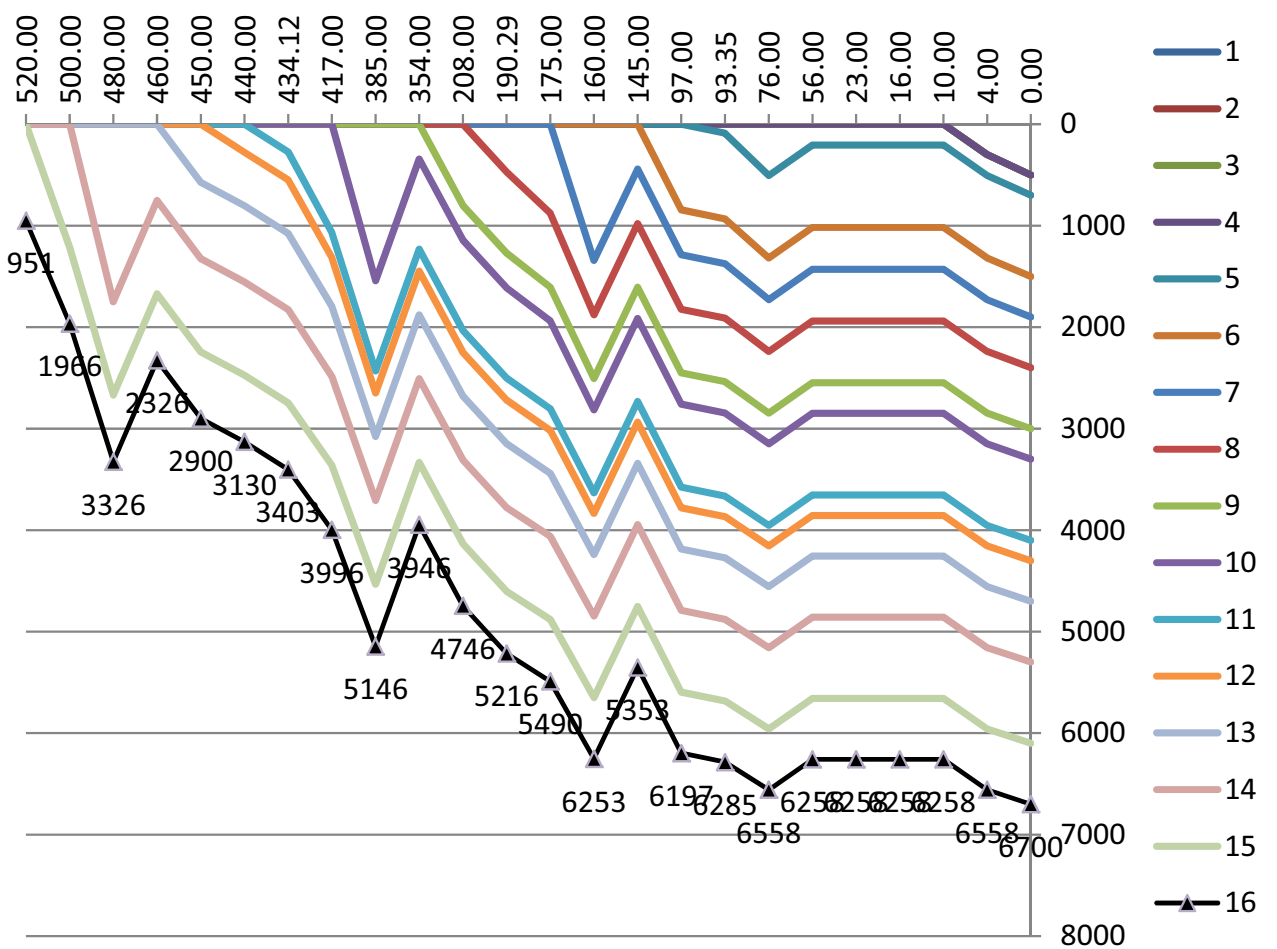


Fig. 5 Curve chart of burial history for strata 2

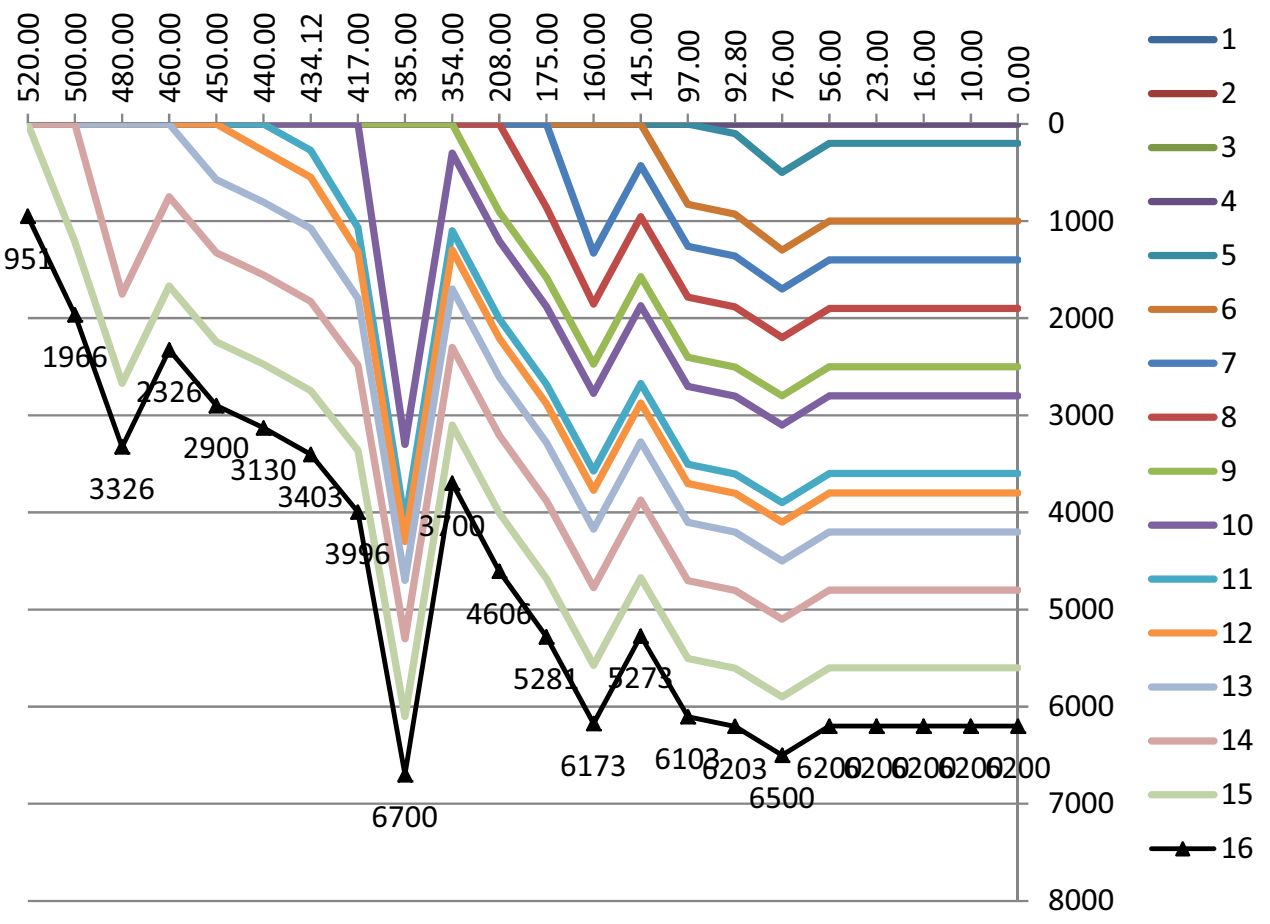

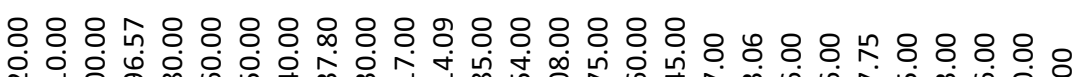

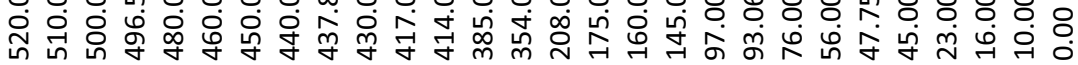

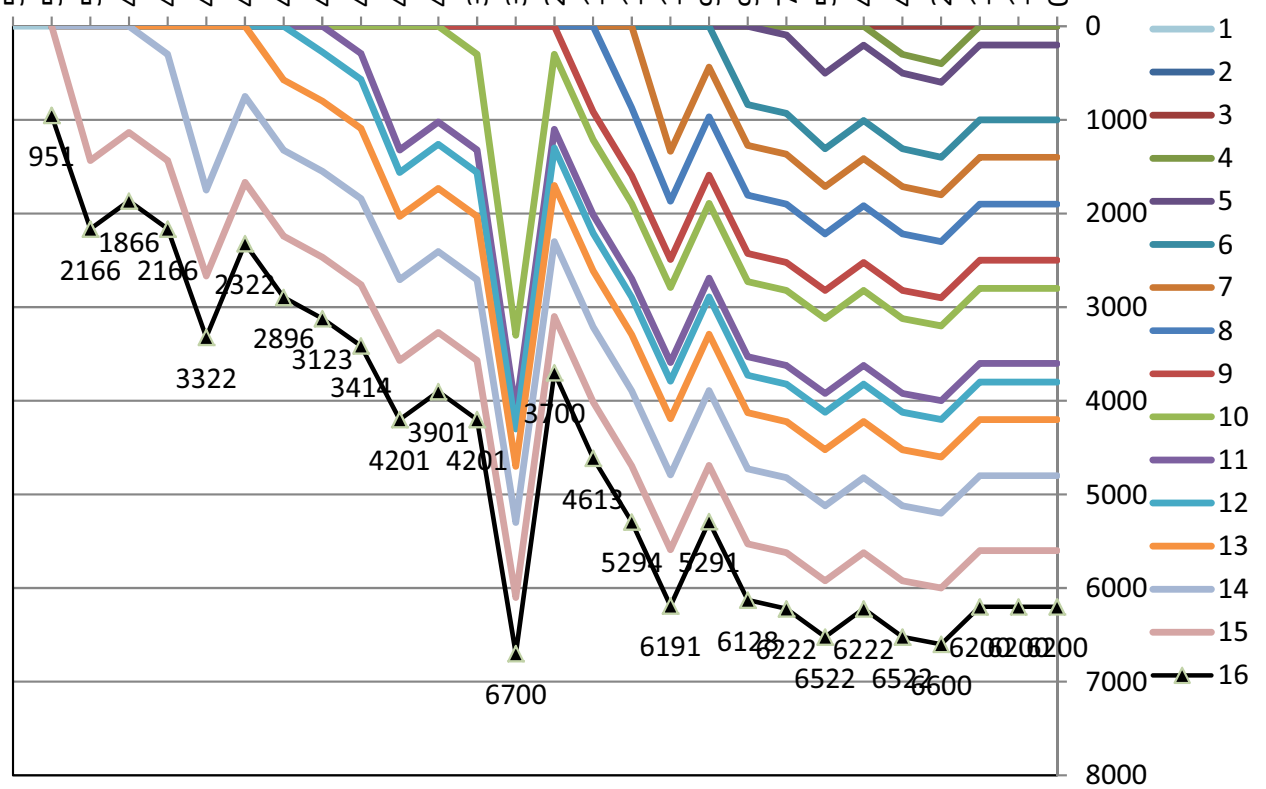

8000
Fig. 6 Curve chart of burial history for strata 3 
Fig. 7 Curve chart of burial history for strata 3 without skeleton thickness considering max depth

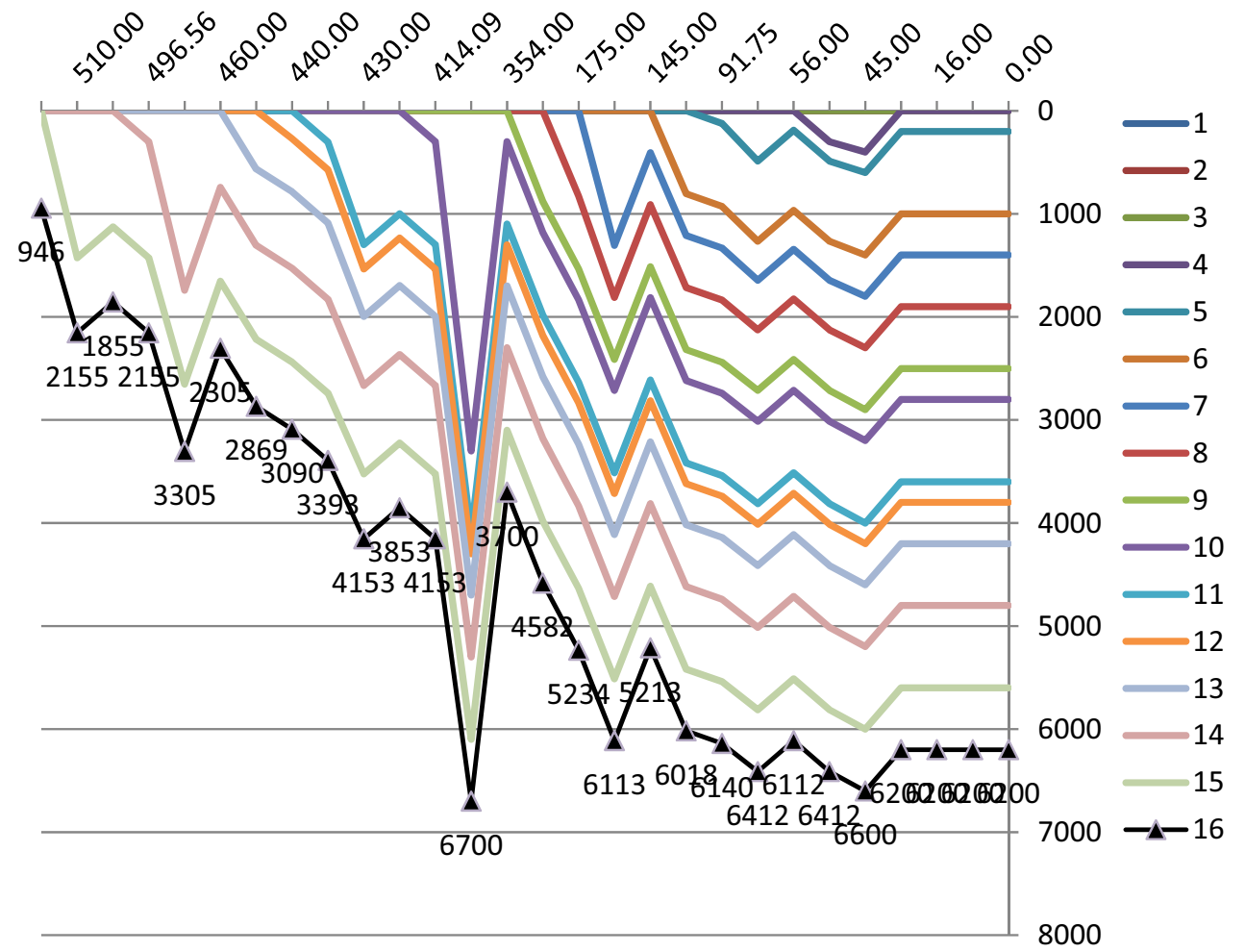

Table 6 Lithological collection class

Table 5 Lithology templates class (lithology class)

\begin{tabular}{lll}
\hline Property & Type & Illustration \\
\hline name & String & Lithology name, e.g., sandstone \\
InitPorosity & Double & Porosity of lithology on surface \\
CompactionFactor & Double & Compaction factor of lithology \\
\hline
\end{tabular}

complex strata. It is convenient to use and high accuracy. Furthermore, it has definite expandability to a certain extent.

\begin{tabular}{lll}
\hline Property & Type & Illustration \\
\hline Lsandstone & Lithology & Strata class, stand for sandstone \\
Lsandsilt & Lithology & Strata class, stand for sandsilt \\
Lshale & Lithology & Strata class, stand for shale \\
Llimestone & Lithology & Strata class, stand for limestone \\
Lconglomerate & Lithology & Strata class, stand for conglomerate
\end{tabular}

Remark: this class is static collection class. It can be extended if need through adding new lithology 
Table 7 Strata class (layer class in computer model)

\begin{tabular}{lll}
\hline Property & Type & Illustration \\
\hline LayerName & String & Strata name, e.g., Q, N2 \\
Base & Double & Bottom boundary \\
Top & Double & Top boundary \\
PresentThickness & Double & Strata thickness, unit: $\mathrm{m}$ \\
ErosionThickness & Double & Strata erosion thickness, unit: $\mathrm{m}$ \\
DepositionAgeFrom & Double & Start time of deposition, unit: Ma \\
DepositionAgeTo & Double & End time of deposition, unit: Ma \\
ErosionAgeFrom & Double & Start time of erosion, unit: ma \\
ErosionAgeTo & Double & End time of erosion, unit: ma \\
Rock & Lithology & Lithology of strata \\
RockVol & double & Skeleton thickness, unit: $\mathrm{m}$ \\
PorosityVol & Double & Volume of porosity, unit: $\mathrm{m}$ \\
\hline Method (parameter 1, parameter 2$)$ & Type & illustration \\
\hline setPresentthickness() & Void & Compute strata thickness \\
setPorosityVol() & Void & Compute volume of porosity \\
setPorosityVol(double Top, double Base) & Void & Compute volume of porosity with parameters \\
setRockVol() & Void & Compute skeleton thickness for property RocVolk \\
BackStripping(double step =1.0, double preci=1.0) & void & Implement back-stripping algorithm of single strata \\
\hline
\end{tabular}

Table 8 BurialHis class

\begin{tabular}{lll}
\hline Property & Type & Illustration \\
\hline Layer & Layer[] & Strata array \\
Result & SortedList $<$ double, Layer[] $>$ & Key-value set for time and strata array \\
\hline Method & Type & Illustration \\
\hline BurialBackStrip() & Void & Core algorithm to restore stratigraphic column \\
AddTime(double T) & Layer[] & Compute the stratigraphic column in time T \\
ExportCSV_Burial(string filePath) & Void & Export the data of bottom boundary into CSV file \\
\hline
\end{tabular}

Acknowledgements Thanks for support from Science and Technology Department Research Plan of Shaanxi province Granted number 2016GY-106, Social Science Foundation of Shaanxi province Granted Number 2015R026, and Education Department Research Plan of Shaanxi province Granted Number 15JZ047 and Xi' an Shiyou University Postgraduate Cultivation Plan of Innovation and Practical Ability with project ID YCS18111008. We thank to reviewers for their valuable comments very much.

\section{Compliance with ethical standards}

Conflict of interest The authors declare that there are no conflicts of interest regarding the publication of this paper.

Open Access This article is distributed under the terms of the Creative Commons Attribution 4.0 International License (http://creativeco mmons.org/licenses/by/4.0/), which permits unrestricted use, distribution, and reproduction in any medium, provided you give appropriate credit to the original author(s) and the source, provide a link to the Creative Commons license, and indicate if changes were made.

\section{Appendix}

\section{Establishment of computer model}

Combining math model, input/output design of backstripping algorithm and the design concept of object-orient, this paper has designed data structure and algorithm for back-stripping process. Then some classes have been formed such as lithology templates class (lithology class), lithological set class (lithologies class), layer class (layer class), and stratigraphic column class (BurialHis class). 
1. Lithology templates class (lithology class in computer model) and lithological set class (lithologies class in computer model)

Lithology templates class is the abstract of different lithology, which have the common properties extracted from sandstone, mudstone, and so on. Lithological set is the collection class of various lithology containing sandstone, mudstone, and other common rock. The two classes are list in Tables 5 and 6.

\section{Strata class (layer class)}

Strata class mainly stores each property and method of strata. The strata thickness, top and bottom boundaries, and skeleton thickness have been union though private method in class. It can be shown in Table 7.

\section{Stratigraphic column class (BurialHis class in computer)}

This class regard one-dimensional array which stand for the current stratigraphic column as input of algorithm and make key-value set expressed by data type Dictionary $<$ double age, Layer[] layer $>$ reflect the relation of strata column and time. Material element in class is listed in Table 8.

\section{References}

Allen PA, Allen JR. Basin analysis principles and applications. Balckwell Scientific Publications, London

Anty LF (1930) Density, porosity, and compaction of sedimentary rocks. AAPG Bull 14(1):1-24

Baozhen Y (2006) Establishment of computer model for basin burial history restoration - application of object oriented method. Nat Gas Ind 26(1):37-39

Dengfeng Q, Shuangjian L, Yusong Y, Xiaoping M, Yan Z, Dongsheng S (2015) Geohistory modeling and its petroleum geological significance of Middle-Upper Yangtze area. Pet Geol Recovery Effic 22(04):6-13

Galushkin Yu, Eloghbi S, Sak M (2014) Burial and thermal history modeling of the Murzuq and Ghadames Basin (LIBYA) using the GALO computer programme. J Pet Geol 37(1):71-94

Gongxiang C (1996) Quantitative calculation of stratum compaction recovery. J Jianghan Pet Inst 18(01):1-6
Handhal AM, Muwafaq F, Al-Shahwan et al (2014) Analysis of burial history for Mesopotamian basin, southern Iraq. Iraqi $\mathbf{J}$ Sci 55(3B):1292-1311

Hedberg HD (1936) Gravitational compaction of clays and shales. Am J Sci 31(5):241-287

Jiaren Y, Mingde L (1995) Review of basin simulation of geological history. Geol Sci Technol Inf 14(02):45-51

Kaijun T, Pingsheng W, Ximin L, Zhonghai M (2005) Research on quantitative resumption method of stratum paleothickness and its application-aking ludong area in zhunge' er basin as an example. Nat Gas Ind 25(10):48-50

Kamali MR, Rezaee MR (2003) Burial history reconstruction and thermal modeling at Kuh-E Mond, SW Iran. J Pet Geol 26(4):451-464

Liu Y, Chang X (2003) Modeling for the burial and subsidence history of the Sichuan basin. Chin J Geophys 46(2):283-290

Minkyu W, Daekyo C (2016) Reconstruction of burial history and analysis of the hydrocarbon potential using sedimentary modeling the middle Bengal Fan, Myan. Geosci J 20(6):813-825

Narkiewicz M, Resak M et al (2010) New constraints on the Middle Palaeozoic to Cenozoic burial and thermal history of the Holy Cross Mts. (central Poland). Geol Acta 8(2):189-205

Okui A (1998) Petroleum system evaluation by basin modeling. J Jpn Assoc Pet Technol 63(1):78-91

Paweł K, Magdalena W (2012) Burial history, thermal history and hydrocarbon generation modelling of the Jurassic source rocks in the basement of the Polish Carpathian Foredeep and Outer Carpathians (SE Poland). Geol Carpath 63(4):335-342

Poprawa P, Kosakowski P, Wróbel M (2010) Burial and thermal history of the Polish part of the Baltic region. Geol Q 54(2):131-142

Premarathne U, Suzuki N, Ratnayake N, Kularathme C (2016) Burial and thermal history modlling of the Mannar Basin, Offshore Sri Lanka. J Pet Geol 39(2):193-213

Senglaub Y, Littke R, Brix MR (2006) Numerical modelling of burial and temperature history as an approach for an alternative interpretation of the Bramsche anomaly, Lower Saxony Basin. Int J Earth Sci 95(2):204-224

Van Keer I, Ondrak R, Muchez P et al (1997) Burial history and thermal evolution of Westphalian coal-bearing strata in the Campine Basin (NE Belgium). Geol Mijnbouw 76(4):301-311

Wei L (1996) Summary of reconstruction of strata denudation thickness. China Offshore Oil Gas 10(03):33-37

Xiangdong L, Gang C, Jiuyong L, Youbin H, Mingji Z (2010) Analysis method and research status of subsidence history. J Oil Gas Technol 32(05):199-203

Xiaoping M, Shaohu L, Gang L, Chonglong W (1998) Back-stripping method under complex conditions-maximum depth method. J China Univ Geosci (Social Sciences Edition) 23(03):61-64

Xiaorong L (2004) Quantitative analysis on overpressuring mechanism resulted from tectonic stress. Chin J Geophys 47(6):1086-1093 